\title{
VIABILIDADE DA APLICAÇÃO DO TESTE TUBERCULÍNICO COM O DERMO-JET
}

Roberto Brólio*

Ricardo Veronesi **

Celso Carmo Mazza***

Chaie Feldman***

Roberto Focaccia***

Hebe A. Cardoso Alves ****

RSPU-B/316

Brólio, R. et al. - Viabilidade da aplicação do teste tuberculinico com o dermo-jet. Rev. Saúde públ., S. Paulo, 10:227-31, 1976.

Resumo: Foram estudadas as reações de hipersensibilidade tuberculinica induzidas por aplicaçōes simultaneas, em adultos jovens, de tuberculina (PPD. .RT-23, 2UT), com agulha e seringa e com o dermo-jet. Foram encontrados $61.3 \%$ de reatores nas aplicacóes com agulha e seringa para $40,0 \%$ de reatores nas aplicacóes com o dermo-jet. Os resultados não säo considerados favoráveis ao uso do injetor a jato na pratica corrente de aplicacão do teste tuberculinico.

Unitermos: Tuberculose. Teste tuberculinico. Dermo-jet.

\section{N T R O D U C $\tilde{A} O$}

O valor do teste tuberculínico. aplicado com agulha e seringa (Teste de Mantoux) conforme recomendação da Organização Mundial da Saúde (OMS), é reconhecido internacionalmente pela sua eficácia, permitindo diagnosticar, com grande margem de segurança, os organismos infectados pelo Mycobacterium tuberculosis: pelo Iycobacterium bovis, pelo BCG ou por micobactérias atípicas.

Na prática não é possível distinguir. pela reatividade tuberculínica, se a reação local é devida a uma infecção natu- ral por germes virulentos ou à vacinação pelo BCG, pois a hipersensibilidade desenvolvida por uma vacina eficaz pode ser tão forte quanto a que é induzida por bacilos virulentos.

Além do valor qualitativo da prova, que permite distinguir os indivíduos que reagem, daqueles que não reagem. ela tem também um valor quantitativo. possibilitando separar os que reagem, em dois grupos, reatores fracos e reatores fortes.

Nos países onde é comum a infecção por micobactérias atípicas, as reações fra-

* Do Departamento de Epidemiologia da Faculdade de Saúde Pública da USP. Av. Dr. Arnaldo. 715 - São Paulo, SP - Brasil.

* Do Departamento de Dermatologia e Doenças Tropicais e Infecciosas. Faculdade de Medicina da USP. Av. Dr. Arnaldo, 455 - São Paulo, SP - Brasil.

*** Do Hospital Emilio Ribas. Av. Dr. Arnaldo, 165 - São Paulo, SP - Brasil.

**** Do Centro de Saúde Geraldo de Paula Souza - Faculdade de Saúde Pública da LSP. Ar. Dr. Arnaldo, 71う — São Paulo, SP - Brasil. 
BRólo, R. et al. - Viabilidade da aplicaçāo do teste tuberculínico com o dermo-jet. Rev. saúde públ., S Paulo, 10:227-31, 1976.

cas. entre 5 e $9 \mathrm{~mm}$ de diâmetro transversal da enduração, são atribuídas a infecçôes por esses microrganismos. Na verdade, reações fracas podem indicar também uma infecção recente. durante a fase de implantação e multiplicação dos bacilos no organismo, ou a uma infecção por germes pouco virulentos, ou a uma infecção causada por pequena quantidade de bacilos ou ainda a uma incapacidade reacional, por baixa resistência do organismo. Em contra partida, as reações fortes, acima de $10 \mathrm{~mm}$ de diâmetro de enduração, principalmente em crianças de pouca idade e nas viragens recentes, mesmo sem alterações radiológicas pulmonares. indicam certa gravidade, merecendo cuidados especiais de quimioprofilaxia ou de quimioterapia.

A hipersensibilidade tuberculínica se desenvolve depois de 3 a 8 semanas da infecção inicial, e uma vez adquirida. tende a persistir, embora possa apresentar variaçōes de intensidade no decorrer dos anos. Ela pode diminuir ou desaparecer na idade avançada, nos estados febris. como sarampo ou outras doenças exantemáticas, com a administração de certas vacinas a vírus. na sarcoidose. na tuberculose evolutiva grave e com a administração de drogas imunossupressoras. Pode, ainda. diminuir ou desaparecer quando o tratamento da infecção é feito precocemente ${ }^{3}$ Quando uma pessoa apresentou hipersensibilidade tuberculínica há muito tempo e faz o teste de Mantoux, o resultado pode ser negativo ou duvidoso. e a repetição do teste depois de pouco tempo pode dar reator forte, o que não deve ser interpretado como conversão, mas estímulo induzido pela aplicação anterior.

Quando o teste é aplicado em larga escala, numa população. tem o valor de diagnóstico epidemiológico, permitindo conhecer a prevalência $\mathrm{da}$ infecção tuberculosa e avaliar a extensão da disseminação do bacilo na comunidade. A Comissão de Peritos da OMS $^{\circledR}$ valoriza o índice de prevalência da infecção tuberculosa co- mo dos mais importantes, para avaliar a magnitude do problema, como base para a elaboração de programas de luta antituberculose.

A aplicação do teste de Mantoux apresenta, contudo, certa dificuldade, principalmente em programas de saúde pública, exigindo pessoal previamente treinado e locais adequados para a sua execução. Com o fim de estudar um método de aplicação de fácil execução e que tenha a mesma sensibilidade do teste de Mantoux, são pesquisados outros métodos, em ensaios controlados, visando sua maior viabilidade em programas de massa, em termos de cohertura e custo, na unidade de tempo.

Em nosso meio tem sido amplamente estudado, nos últimos anos, o método da multipuntura ou Tine Test de Rosenthal $1,2,5,7,10$.

O presente trabalho vem ao encontro do objetivo de pesquisar a viabilidade de execução do teste tuberculínico aplicado a jato, método já utilizado por outros autores em estudos semelhantes ${ }^{6, S, 12}$.

\section{MATERIAL E MÉTODOS}

Os testes tuberculínicos foram aplicados em recrutas do $16 .^{\circ}$ Batalhão da Polícia Militar de São Paulo, sediado na Cidade Universitária. São pessoas do sexo masculino, com média de idade de 20 anos, pertencentes aos diferentes grupos étnicos inerentes a nossa população.

0 teste foi aplicado no terço inferior da face anterior do antebraço, simultaneamente, com agulha e seringa no braço esquerdo e com o dermo-jet no braço direito, na mesma dose, de $0.1 \mathrm{ml}$ em cada aplicação.

A aplicação no braço esquerdo, com agulha e seringa. foi feita por pessoa previamente treinada e com experiência na realização de testes tuberculínicos, obedecendo à técnica recomendada pelo Serviço Nacional de Tuberculose * atual Divisão Nacional de Tuberculose (DNT). A 
BRolio, R. et al. - Viabilidade da aplicação do teste tuberculinico com o dermo-jet. Rev. Saúde públ., S. Paulo, 10:227-31, 1976.

aplicação no braço direito, com o dermo-jet foi feita por pessoa não treinada e que recebeu uma prévia explicação sobre o manuseio do aparelho.

A tuberculina utilizada na aplicação dos testes foi a mesma, de origem dinamarquesa, preparada pelo Serum Institute de Copenhague, diluída e distribuída pela DNT. E uma tuberculina purificada
(PPD), pertencente ao lote Rt-23, contendo 0,04 mcgs por $0,1 \mathrm{ml}(2 \mathrm{UT})$.

As seringas e agulhas utilizadas são padronizadas, de vidro com êmbolo de metal e agulhas de platina, fornecidas pela DNT. O termo-jet, aparelho de fabricação inglesa, produzido pela Schuco International, London Ltd, é de propriedade de um dos autores.

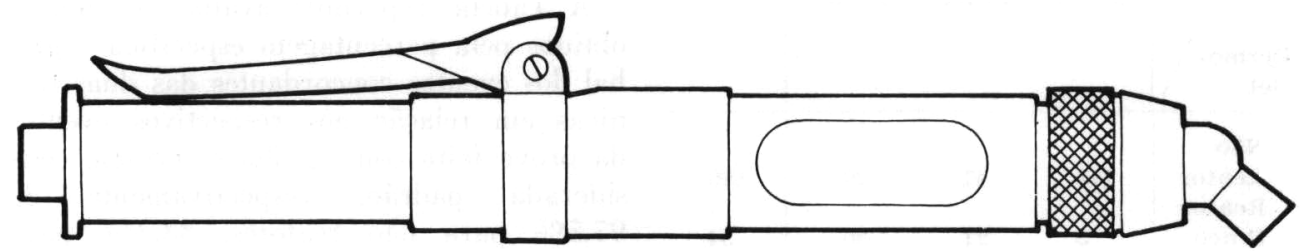

Figura - Dermo-jet. Aparelho de fabricação da Schuco International London Ltd., utilizado na aplicação de testes tuberculínicos em adultos jovens. São Paulo, Brasil, 1975.

Os testes foram aplicados e lidos numa sala previamente preparada. A leitura foi feita 72 horas depois da aplicação por uma pessoa treinada na leitura de testes tuberculínicos, sendo considerados não reatores aqueles cuja enduração foi igual ou inferior a $4 \mathrm{~mm}$, reatores fracos os que tiveram de 5 a $9 \mathrm{~mm}$ e reatores fortes os que tiveram 10 ou mais $\mathrm{mm}$ de enảuração.

\section{R E S U L T A D O}

Os resultados da aplicação do teste tuberculínico feitos em 315 pessoas constam das Tabelas 1 e 2.

O desenvolvimento das reaçôes locais, o aspecto e a consistência das endurações dos testes aplicados com dermo-jet foram idênticos aos obtidos com a aplicação com agulha e seringa.

Para um total de 315 testes aplicados com dermo-jet houve $60,0 \%$ de não reatores, $17,1 \%$ de reatores fracos e $22,9 \%$ de reatores fortes e, para o mesmo número de testes aplicados com agulha e se- ringa houve $38,7 \%$ de não reatores, $20,0 \%$ de reatores fracos e $41,3 \%$ de reatores fortes (Tabela 1).

TA B E L A I

Distribuição dos resultaaos da aplicação de testes tuberculínicos, com dermo-jet e com agulha e seringa, em adultos da Polícia Militar de Sāo Paulo, 1975

\begin{tabular}{l|c|c|cc}
\hline & \multicolumn{2}{|c|}{ Dermo-jet } & \multicolumn{2}{|c}{ Agulha e seringa } \\
\cline { 2 - 5 } Resposta & N.0 & $\%$ & N.o & $\%$ \\
\hline $\begin{array}{l}\text { Não } \\
\text { Reator }\end{array}$ & 189 & 60,0 & 122 & 38,7 \\
$\begin{array}{l}\text { Reator } \\
\text { Fraco } \\
\text { Reator }\end{array}$ & 54 & 17,1 & 63 & 20,0 \\
Forte & 72 & 22,9 & 130 & 41,3 \\
\hline Total & 315 & 100,0 & 315 & 100,0 \\
\hline
\end{tabular}

A Tabela 2 mostra a correlação dos resultados obtidos nas aplicações do teste, com o dermo-jet e com a seringa e agulha. 
BRólo, R. et al. - Viabilidade da aplicaçāo do teste tuberculínico com o dermo-jet. Rev. Saúde públ., S. Paulo, 10:227-31, 1976.

TABELA 2

Distribuiçāo dos reatores e nāo reatores ao teste tuberculinico (PPD. Rt-23, 2UT), aplicado simultaneamente com agulha e seringa e com o dermo-jet, em adultos da Polícia Militar de São Paulo, 1975

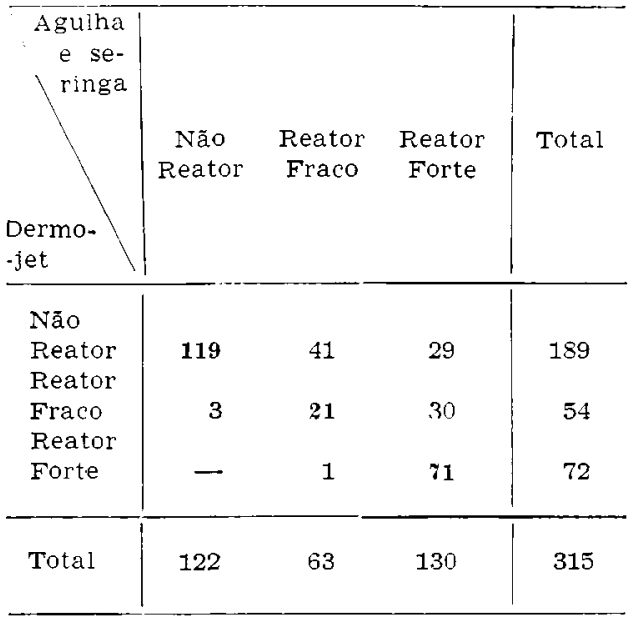

\section{COMENTARIOS}

O presente trabalho, baseado no emprego do dermo-jet para a aplicação do teste tuberculínico, representa um esforço válido no sentido de pesquisa de uma técnica que possa oferecer maiores facilidades operacionais, principalmente em programas de saúde pública, do que a que se tem com o emprego da tradicional prova de Mantoux, feita com agulha e seringa.

Contudo, a análise dos resultados obtidos indica que o dermo-jet ainda não pode ser utilizado na prática corrente para a aplicação do teste tuberculínico.

Os resultados apresentados na Tabela 1 mostram-nos que nas aplicações com o injetor a jato houve $60.0 \%$ de não reatores para $38,7 \%$ nas aplicações com agulha e seringa. uma diferença bastante significativa; o mesmo ocorrendo com as percentagens de reatores fortes, de $22,9 \%$ nas aplicações com o dermo-jet para $41,3 \%$ nas aplicações com agulha e seringa.

A Tabela 2 mostra-nos que entre os não reatores, nas aplicações com dermo-jet. encontra-se um grande número de reatores quando as aplicaçōes são feitas com agulha e seringa, o mesmo ocorrendo com o grupo de reatores fracos onde houve um pequeno número de não reatores c um grande número de reatores fortes nas aplicações com agulha e seringa. Nos resultados de reatores fortes com dermo-jet houve, praticamente, concordância com os resultados obtidos com agulha e seringa.

A Tabela 2 permite avaliar os índices obtidos pela percentagem específica e global dos eventos concordantes das duas técnicas em relação aos respectivos eventos da prova feita com agulha e seringa, considerada padrão, respectivamente de $97.5 \%$ para não reatores. $33.3 \%$ para reatores fracos, $54.6 \%$ para reatores fortes e $66.9 \%$ para os eventos globais. Esses ralores expressam a especificidade e a sensibilidade ${ }^{11}$ da técnica do dermo-jet em relação à da agulha e seringa. onde a especificidade é de $97,5 \%$ para os não reatores e a sensibilidade é de $33.3 \%$ para reatores fracos e de $54,6 \%$ para reatores fortes. Mesmo reunindo os reatores fracos e fortes do dermo-jet. concordantes com os respectivos reatores obtidos com agulha e seringa. temos $63.7 \%$. sensibilidade considerada insatisfatória para recomendar o emprego do dermo-jet nas atividade de rotina de pesquisa da sensibilidade tuberculínica.

Para a utilização da técnica em larga escala é importante saber qual a probabilidade de uma pessoa não-reatora com o dermo-jet ser realmente não-reatora com agulha e seringa e, inversamente, qual a probabilidade de uma pessoa reatora com o dermo-jet ser realmente reatora. O valor predictivo do teste negativo mostra-nos que dos 189 eventos não-reatores com o dermo-jet, apenas 119 o são realmente, isto é, 0,370 ou $37.0 \%$. o que quer dizer que houve uma alta percentagem de falsos negativos. $O$ valor predictivo do teste positivo é de $38,9 \%$, para reatores fracos e de $98.6 \%$ para reatores fortes. De 54 reatores fracos com o dermo-jet apenas 21 o são realmente. indicando uma alta per- 
BRoLIO, R. et al. - Viabilidade da aplicação do teste tuberculínico com o dermo-jet. Rev. Saude públ., S. Paulo, 10:227-31, 1976.

centagem de falsos positivos para reatores fracos. Apenas os reatores fortes ao dermo-jet apresentam uma alta probabilidade de ser realmente reatores fortes.

As discordâncias encontradas podem ser devidas ao próprio injetor que pode falhar e não inocular, em cada aplicação, a quantidade exata de substância programada, ou ser devida à dispersão do inóculo, pois com a força do injetor a jato a substância inoculada ultrapassaria a ca- mada dérmica, difundindo-se no tecido celular subcutâneo.

\section{A G R A E C I M E T OS}

Ao Professor José Maria Pacheco de Souza, do Departamento de Epidemiologia da Faculdade de Saúde Pública USP, pelas sugestões para a análise estatística dos dados apresentados.

RSPU-B $/ 316$

BRólio, R. et al. - [The viability of the tuberculin skin test applied with the dermo-jet]. Rev. Saúde públ., S. Paulo, 10:227-31, 1976

SUMMARY: Hipersensibility reaction to the tuberculin test was studied using two types of simultaneous application in young male patients: usual syringe and needle and dermo-jet. The results revealed $61.3 \%$ positive reactions with the use of syringe and needle, vs. $40.0 \%$ using dermo-jet. These results show that the use of conventional syringe and needle in tuberculin skin tests is still the best current practice.

UNITERMS: Tuberculosis. Tuberculin test. Dermo-jet.

\section{REFERENCIAS BIBLIOGRÄFICAS}

1. AZEVEDO, J.F. \& TORRES, M.F. Tine Test e PPD na investigação da alergia tuberculínica. Fôtha méd., 66:149-53, 1973 .

2. BETHLEM, N.M. et al. - TB Tine Test - verificação da viabilidade de uso em nosso meio. Fôlha méd., $\mathbf{7 1}$ : 201-4, 1975 .

3. BRólio, R. - Papel da quimioterapia no controle de duas epidemias de tuberculose em crianças menores de 3 anos de idade, numa creche no Município de São Paulo (Brasil) em 1967 e 1969. Rev. bras. Clin. Terap., $4: 275-80,1975$.

4. CAMPANHA NACIONAL CONTRA A TUBERCULOSE. Comissão Técnica Prova tuberculínica em saúde pública (2.a recomendação). Rev. serv. nac. Tuberc., 12:219-30, 1968.

5. CARVALHO, E.S. \& BAROLLO, C.R. - Uso do Tine-Test no diagnóstico da infeccão tuberculosa. Rev. Ass. méd. Brasil., 21:270-2, 1975.

6. DULL, H.B. et al. - Jet injector tuberculin skin testing. A comparative evaluation. Amer, Rev. resp. Dis., 97: 38-45, 1968.
7. IIMA FILHO, M.T. et al. - Estudo comparativo entre Tine test e a reação do Mantoux com PPD, Rt-23, 2UT. Fôlha méd., 67:105-9, 1973.

8. MACLEAN, R.A. - Tuberculin testing antigens and techniques. Chest, 68 (supl.): 455-9, 1975 .

9. ORGANIZACEO MUNDIAL DA SAUDE. Expert Committee on Tuberculosis Geneva, 1964. Report, 8 $^{\text {th }}$, Geneva, 1964. (Techn. Rep. Ser., 290).

10. PERFEITO, J.B. et al. - Estudo comparativo entre Tine test de Rosenthal e a reação de Mantoux com PPD 2 undades. Fôlha méd., 67: $97-103,1973$.

11. VECCHIO, T.J. - Predictive value of a single diagnostic test in unselected populations. New Engl. J. Med., 274:1171-3, 1966.

12. VERONESI, $R$, et al. - Intradermo diagnóstico simultâneo com antígenos inoculados a jato. Importância em inquéritos imuno-epidemiológicos. Rev. Hosp. clin. Fac. Med. S. Paulo, $30: 357-61,1975$.

Recebido para publicaçio em 09/03/1976 Aprovado para publicacio em 12/03/1976 